\title{
HISTORIA DE LAS RELACIONES DIPLOMÁTICAS COSTA RICA-PERÚ DURANTE EL PERÍODO DE LA CAMPAÑA NACIONAL CONTRA LOS FILIBUSTEROS (1856-1857): EL CASO DEL EMPRÉSTITO PERUANO
}

\author{
HISTORY OF COSTA RICA-PERU DIPLOMATIC \\ RELATIONS DURING THE NATIONAL CAMPAIGN \\ AGAINST THE FILIBUSTERS (1856-1857): THE \\ PERUVIAN LOAN'S CASE
}

\author{
Sara Mora Ugalde ${ }^{1}$ \\ ORCID: 0000-0002-3051-4139
}

Silvia Monge Blanco ${ }^{2}$

ORCID: 0000-0002-1933-1200

\section{Adriana Mora Rodríguez ${ }^{3}$}

ORCID: 0000-0003-4843-9218

\section{RESUMEN}

El presente artículo tiene por objetivo estudiar la historia diplomática entre Costa Rica y el Perú durante la campaña contra los filibusteros, particularmente el empréstito peruano. Para esto se realizó una revisión de correspondencia diplomática y obras de autores costarricenses y peruanos en las que se hace mención del tema en estudio. Mediante el análisis de discurso se establecieron categorías para identificar las principales razones que posibilitaron que este país de América del Sur brindara su apoyo a la causa centroamericana y concediera un préstamo a Costa Rica; motivos expuestos, en particular, por el Ministro peruano Pedro Gálvez, donde se evidencia una evolución a partir de justificaciones centradas en la caracterización de Costa Rica, rasgos de la contienda, para finalmente exponer cualidades atribuidas al Perú, que refuerzan la conveniencia de concretar la ayuda al país centroamericano.

Palabras clave: Centroamérica; Costa Rica; Perú; Campaña Nacional de 1856; empréstito; filibusteros

\section{ABSTRACT \\ This article aims to study the diplomatic history between Costa Rica and Peru during the campaign against the filibusters, particularly the Peruvian loan case. This study included diplomatic correspondence and some works of Costa Rican and Peruvian authors in which}

1 Universidad Nacional, Costa Rica. Máster en Bioética. Correo electrónico: arq.sara.mora@gmail.com

2 Ministerio de Relaciones Exteriores y Culto, Costa Rica. Máster en Diplomacia. Correo electrónico: silmonge19@gmail.com

3 Embajada del Perú en Costa Rica. Licenciatura en Relaciones Internacionales. Correo electrónico: adrim02@hotmail.com 
this subject was analyzed. By using discourse analysis, categories were stablished to identify the main reasons why this South American country conceded a loan to Costa Rica. These reasons were expressed mainly by the Peruvian Minister Pedro Gálvez, showing an evolvement in the justifications for the loan, starting with the characterization of Costa Rica, continuing with issues about the armed conflict at that time, to finally expose qualities attributed to Peru that reinforced the convenience of securing help to the Central American country.

Keywords: Central America; Costa Rica; Peru; 1856 Campaign; loan; filibusters

\section{Introducción}

Tras la independencia de España, las nuevas naciones latinoamericanas empezaron a entablar relaciones diplomáticas entre sí. Muchos de los primeros acercamientos estuvieron motivados por elementos circunstanciales de la época y el deseo de apoyo mutuo para hacer frente a los problemas e intereses comunes. Ello incluyó la lucha contra la presencia de expediciones foráneas como la que lideró William Walker, que buscaba expandirse por la región, aprovechando el débil escenario político y económico que afrontaban los nuevos Estados.

Una de las etapas históricas más importantes para el Estado costarricense, y con un fuerte peso en el imaginario de la sociedad, aún en la actualidad, fue la campaña contra los filibusteros. Sin embargo, existen aspectos más puntuales de esa época que han sido apenas expuestos y que incidieron a posteriori de la contienda, como es el caso del empréstito otorgado por la República del Perú al Gobierno de Costa Rica.

Para la historia costarricense dicha campaña es un hito desde el ámbito político-militar, pero también significó un desgaste económico, social y político para el Estado. En este artículo se analiza la coyuntura sociopolítica que permite brindar un panorama cercano de las variables y condiciones que propiciaron que el Gobierno peruano apoyara al Estado costarricense con un préstamo, el cual, aunque llegó cuando ya había terminado la guerra, significó un empuje importante para las arcas estatales costarricenses, que afrontaron una aguda crisis económica.

Para lograr una mejor comprensión de las variables que destacaron en dicho escenario, se tomaron como base dos ejes: el primero, la correspondencia diplomática entre el Gobierno peruano y el costarricense; el segundo, libros de análisis de la campaña que permiten un mejor discernimiento de la correspondencia. También, se planteó el estudio de tres áreas: una contextualización que señala los principales cánones bajo los cuales se desarrolla la coyuntura analizada; las relaciones diplomáticas Costa Rica-Perú y, finalmente, los factores que motivaron al país sudamericano a conceder el préstamo a Costa Rica. 
El caso del empréstito peruano es una oportunidad en el estudio de las relaciones internacionales y de la política exterior, en particular para conocer los lazos históricos que han existido en momentos claves de Costa Rica y también para reconocer antecedentes sobre la gestión de las relaciones diplomáticas, que muestran cómo se consiguió el apoyo económico por el reconocimiento de la causa a la que se enfrentó el Estado, en uno de los primeros ejemplos de la cooperación entre ambos países.

\section{Estado de la cuestión}

Numerosos trabajos se han escrito sobre la realidad tanto peruana como costarricense durante la década de los años cincuenta del siglo XIX. A pesar de ello, la mención al tema del empréstito peruano ha sido escasa, por lo que aún no se ha realizado un análisis detallado del tema. El embajador costarricense, Jorge Sáenz, en su libro Historia Diplomática de Costa Rica (1821-1910), evoca los principales hitos de la política exterior de Costa Rica a mediados del siglo XIX. Entre ellos señala la lucha contra los filibusteros y la firma del Tratado Continental. También, hace un recuento de la situación económica del país, al realizar una breve mención sobre el empréstito otorgado por el Perú a Costa Rica (Saénz, 1996).

Por otra parte, la diplomática peruana, Rosa Garibaldi, en su libro La política exterior del Perú en la era de Ramón Castilla, destaca los principales ejes que guiaron la política exterior del presidente, quien gobernó en el Perú en dos ocasiones, de 1845 a 1851 y de 1855 a 1858 . Durante su último mandato tuvo lugar la gesta contra el ejército filibustero en Centroamérica. En este contexto, se destaca la importancia concedida a la defensa hemisférica y el Tratado Continental de 1856 (Garibaldi, 2003).

De igual manera, la doctora Carmen Fallas Santana, en varias de sus obras, se refiere a los aspectos que caracterizaron la situación política y socioeconómica de Costa Rica durante el siglo XIX. Uno de los elementos más importantes a tener en consideración fue el manifiesto interés de los Estados Unidos en construir un canal interoceánico en el istmo centroamericano. Por otro lado, en cuanto a la situación interna del Estado costarricense, al finalizar la primera mitad del siglo XIX este se encontraba en una época de consolidación de su poder ejecutivo, además, contaba con una pujante economía y carecía de deuda externa (Fallas Santana 2004; Fallas, 2011).

Es en este contexto que tiene lugar el empréstito otorgado por el Perú en 1858. El monto concedido fue de cien mil pesos, con una tasa de interés del $4.5 \%$, 
por un plazo de diez años. Cleto González Víquez, en su artículo El empréstito peruano a Costa Rica (1925), realiza una descripción de los hechos y señala que en lo relativo a la cancelación de la deuda nunca se efectuó ningún pago, ni del principal ni de sus intereses. A pesar de ello, el Perú no presentó reclamo alguno hasta en 1879 en el marco de la guerra del Pacífico (González, 1925).

En cuanto a la situación interna del Perú, el historiador Jorge Basadre destaca que para mitad del siglo XIX el guano, uno de los productos de exportación del Perú, tiene un importante auge en los mercados europeos. No obstante, el país debió hacer frente a una complicada situación económica que lo llevó a endeudarse. Esto se sumaba a la deuda externa que provenía desde los primeros años de vida independiente. Además, a inicios de la década de los cincuenta de ese siglo, tienen lugar una serie de reformas fiscales que limitan los ingresos de la hacienda pública. Por otra parte, en esta época el país enfrentó una guerra civil que demandó cuantiosos gastos (Basadre, 2005).

Es importante señalar que, si bien existen varios trabajos relacionados con la política exterior de defensa continental seguida por el Perú a mediados del siglo XIX y la ardua campaña emprendida por Centroamérica contra el ejército filibustero dirigido por William Walker, poco se ha hablado sobre la construcción de la relación diplomática entre el Perú y Costa Rica. En tal sentido, aunque hay algunas menciones del empréstito que otorgó el Perú a Costa Rica con ocasión de la guerra emprendida contra los invasores norteamericanos, no se ha realizado un estudio detallado sobre este acontecimiento y los factores que lo motivaron.

\section{Metodología}

Para efectos de la presente investigación se utilizó el análisis de discurso. Esta metodología busca identificar la relación entre el texto (lo escrito) y el contexto, en el cual surgieron dichos escritos, a partir de un estudio sistemático de las fuentes. Para esto se utilizaron como fuentes primarias 42 documentos de correspondencia diplomática entre Costa Rica y el Perú, escritos entre el 1 de agosto de 1827 y el 20 de setiembre de 1870, distribuidos en 199 páginas. Ante la ausencia de documentación de la época en el Archivo Nacional de Costa Rica se acudió a los documentos resguardados por el Ministerio de Relaciones Exteriores del Perú, en donde se encuentran las versiones físicas originales de dicha correspondencia, la cual está escrita a mano. Para acceder a ella se solicitó colaboración a la Embajada del Perú en Costa Rica, y por medio de esta representación diplomática se tuvo acceso a las versiones digitalizadas de los originales. 
Si bien la correspondencia diplomática de la época entre Costa Rica y el Perú puede ser muy amplia, se procedió a realizar una selección de la que podría ser de utilidad para la investigación. En tal sentido, de los 42 documentos a los cuales se tuvo acceso inicialmente, se eligieron 25 , en los cuales se hacía referencia a la situación que afrontaba Centroamérica y Costa Rica en relación con la llegada de los filibusteros y, posteriormente, con la solicitud, concesión y pago del empréstito de parte del Perú a Costa Rica. La mayoría de estos documentos son cartas escritas por el señor Pedro Gálvez, quien era el representante del Gobierno peruano para Centroamérica.

Las categorías de análisis se elaboraron a partir de la identificación de palabras clave, en cada uno de los documentos, y, más tarde, se escogieron las frases más representativas, en las cuales quedan plasmadas, de manera implícita o explícita, las razones que pudieron haber motivado al Gobierno del Perú a otorgar un empréstito a Costa Rica para atender la situación generada como consecuencia de la presencia de los filibusteros estadounidenses en territorio centroamericano. Las razones expuestas se clasificaron en tres grupos, a partir de un proceso inductivo, que definen con mayor claridad la intención mostrada: razones sobre Costa Rica, características de la contienda y razones para el Perú. Dentro de cada uno se identificaron categorías ejemplificadas con fragmentos textuales. Se complementa, además, con un análisis del contexto, en el que se describen las condiciones en las que se encontraban ambos países.

Para el análisis antes expuesto, se tomó en consideración que el contexto dentro del cual se enmarca el empréstito peruano puede ser analizado desde la teoría realista de las Relaciones Internacionales. Desde esta perspectiva, la unidad de análisis es el Estado, el cual es un actor racional, que actúa en función de la maximización de su poder y donde la seguridad nacional es el principal objetivo. Es decir, la "supervivencia del Estado en un medio hostil, en el que la amenaza es constante y militar" (Barbé, 2007, p. 62).

\section{Hallazgos de la investigación}

\section{Contexto de la concesión del empréstito}

Los Estados Unidos, a pesar de su "Ley de Neutralidad" de 1818, iniciaron un claro proceso expansionista, con un creciente deseo por controlar la mayor cantidad del continente, que se tradujo en políticas para excluir la influencia europea en América. Estas ideas se resumen bajo el título de "Destino Manifiesto" de John O 'Sullivan de 1845: 
La convicción de que es nuestro destino manifiesto de Estados Unidos esparcirnos por todo el continente de que nos deparó la Providencia para que en libertad crezcan y se reproduzcan y se multipliquen anualmente millones y millones de norteamericanos [...] De igual manera este país conquistará o se anexará todas las tierras. (Weinberg, 1968, 36). (Quesada, 2014, p.11)

El Destino Manifiesto y la intensificación de los conflictos entre los estados del norte y los estados del sur de los Estados Unidos, con respecto a la esclavitud, impulsaron el auge del filibusterismo a mediados del siglo XIX. Después, la aprobación de las leyes antiesclavistas "motivó que algunos sureños concibieran planes de expansión hacia México, Centro América y las islas del Caribe [...] para implantar el sistema de producción esclavista" (Fallas, 2011, p. 74); bajo la premisa de que sería una conquista fácil por la creencia en la superioridad racial anglosajona y las guerras civiles locales.

En este contexto tiene lugar la intervención en la región centroamericana por parte de William Walker, un filibustero estadounidense que, "después de fracasar en expediciones en Sonora y Baja California (México) intentó poner en práctica sus proyectos en Nicaragua a partir de 1855" (Fallas, 2011, p.74). Además, la posible creación de una conexión interoceánica en Centroamérica que facilitara la movilización del comercio impulsó el interés de Estados Unidos en la región, como una pieza clave debido a su posición geográfica y las posibilidades de comunicación que podría representar la construcción de un canal interoceánico utilizando el río San Juan, el lago de Nicaragua y los ríos de Lajas y la Flor, o alguno de los otros ríos que por esas inmediaciones desembocan en el Pacífico (Ministerio de Relaciones Exteriores del Perú, 14 de enero de 1857), (Fallas Santana, 2015).

\section{Coyuntura sociopolítica y económica del Estado costarricense}

Debido a la cercanía geográfica, la incursión de William Walker en Nicaragua al mando de un ejército filibustero estadounidense y su alianza con los demócratas nicaragüenses, en un momento de convulsión política en Nicaragua, puso al Gobierno costarricense en estado de alerta (Molina, 2006). El presidente de ese entonces, Juan Rafael Mora Porras, había sostenido como una de las prioridades de su gobierno la estabilidad política, para lo cual realizó una serie de reformas importantes en la organización del ejército (Fallas Santana, 2004).

En cuanto al sector económico, durante los primeros años de la administración de Mora Porras el país no tenía deuda externa y el tesoro público era solvente 
(Fallas Santana, 2004). El café, principal sustento de la economía nacional, estaba siendo muy bien acogido dentro del sector internacional, sobre todo en Inglaterra, y Costa Rica vivió el nacimiento de una élite cafetalera que permitió una mayor movilización de capital (Quesada, 2014). Pese a ello, la gesta contra los filibusteros estaba generando una serie de costes que tornó insuficientes los recursos públicos. Por este motivo, se decidió poner un arancel a las exportaciones del café para hacer frente a los gastos de la campaña (Sáenz, 1996). Además, se impusieron dos empréstitos nacionales forzosos. El primero se ubica en febrero de 1856, por la suma de 100000 pesos, dividido entre las cuatro principales ciudades: San José, Cartago, Heredia y Alajuela. El segundo empréstito tuvo lugar en abril de ese mismo año, por 50000 pesos (Fallas Santana, 2004, p. 55).

En la esfera internacional, en diciembre de 1855, el encargado de negocios de Costa Rica en Washington, Luis Molina, le dirigió una carta al secretario de estado de los Estados Unidos, William Marcy, en la que le expresó la necesidad de llamar su atención sobre la invasión filibustera que estaba teniendo lugar en Nicaragua, sumado al temor por una pronta afectación en Centroamérica. Molina señaló que el Gobierno costarricense esperaba que ese asunto no fuera indiferente a los Estados Unidos, pues su silencio podía inducir a pensar que los filibusteros actuaban con la aprobación de su Gobierno e incrementar el número de aventureros (Fallas Santana, 2015).

\section{Coyuntura sociopolítica y económica del Estado peruano}

A pesar de considerarse como un Estado independiente y con grandes proyecciones en la región de Sudamérica, a mediados del siglo XIX, el Perú estaba pasando por problemas fiscales y ajustes políticos: una creciente deuda externa e interna, una serie de reformas fiscales que limitaron los ingresos de la hacienda pública y una guerra civil (Basadre, 2005).

La coyuntura política del Estado peruano para el año 1856 es una de las etapas fundamentales en el desarrollo de este, ya que se formuló la séptima de las once constituciones que ha tenido el Perú, en medio de una clara convulsión política. Sin embargo, esta nueva Constitución fue un antecedente para la guerra civil entre los años 1856-1858, llamada también "Revolución de Arequipa", en la que se enfrentaron dos caudillos de ideología distinta: liberales (Manuel Ignacio de Vivanco) y conservadores (Ramón Castilla), (Valdivia, 1874).

En este contexto se percibió una disminución en la autoridad del Poder Ejecutivo en la nueva constitución, aprobada en 1856, de carácter liberal, que limitó las 
atribuciones del Jefe de Estado. La guerra civil que afrontaba el país condujo a la anulación de la Constitución y la elección de Ramón Castilla, como presidente, durante los comicios presidenciales y congresales celebrados en 1858, con la posterior promulgación de una nueva Constitución, de carácter moderado, en 1860 (Ayllón, 2017).

\section{Alianzas y tratados hispanoamericanos}

Dos incidentes relacionados con la aplicación de la doctrina del Destino Manifiesto, por parte de Estados Unidos, motivaron la creación de una nueva unión confederativa: la firma del Tratado de los Galápagos en 1854 y el desembarco en Nicaragua de un grupo de filibusteros comandados por William Walker en 1855. Con el primero, Estado Unidos tuvo derecho a la explotación de guano en el archipiélago del Ecuador. Respecto al segundo, el grupo filibustero, cada vez con mayor número de efectivos, buscaba no solo anexar el territorio de Nicaragua, sino incluso cambiar el idioma local de español a inglés, promover la esclavitud y crear un canal interoceánico. Ante esta amenaza de expansionismo estadounidense, los ministros plenipotenciarios y encargados de negocios de las Repúblicas Hispanoamericanas -Costa Rica, El Salvador, Guatemala, México, Nueva Granada, Perú y Venezuela- se reunieron en Washington, el 8 de noviembre de 1856. Como resultado de este encuentro, el 9 de noviembre del mismo año suscribieron un tratado de alianza y unión denominado Confederación de los Estados Hispanoamericanos (De la Reza, 2014).

Con este acuerdo se buscaba contener las expediciones foráneas realizadas en contra del Gobierno de alguna de las repúblicas firmantes, así como garantizar la independencia y soberanía de aquellas. Para ello se comprometen a ayudarse en caso de amenaza de invasión, considerándose enemigo de todos los Estados aliados al enemigo de uno de ellos (Ministerio de Relaciones Exteriores del Perú, 9 de noviembre de 1856).

Por otra parte, el 15 de setiembre de 1856 Chile, Ecuador y Perú suscribieron, en Santiago de Chile, un tratado de unión continental al que eran invitados a unirse todos los países de la América española. El ministro designado del Perú para los Estados de Centro-América, Nueva Granada y Venezuela, recibió la instrucción de procurar que todos los países, o al menos la mayoría de estos, firmaran el Tratado Continental de Alianza y de Amistad sobre la base del celebrado en Chile (Ministerio de Relaciones Exteriores del Perú, 2 de febrero 1857). Costa Rica fue el primer país con el que suscribió el Tratado Continental, el 31 de enero de 1857 (Sáenz, 1996). 


\section{Relaciones diplomáticas Costa Rica-Perú}

En setiembre de 1851, el presidente de Costa Rica, Juan Rafael Mora Porras, nombró a Gregorio Escalante como encargado de negocios de Costa Rica en el Perú; encomendándole la misión de firmar un tratado de reconocimiento, paz, amistad, comercio y navegación con esta nación sudamericana (Ministerio de Relaciones Exteriores del Perú, s.f.a).

El 20 de octubre de 1851, el señor Escalante presentó a don Bartolomé Herrera, Ministro de Relaciones Exteriores del Perú, un proyecto de tratado elaborado por Costa Rica, mismo que se esperaba fuese visto como útil y ventajoso a los intereses de las partes involucradas (Ministerio de Relaciones Exteriores del Perú, s.f.b). En los meses siguientes, Costa Rica realizó persistentes manifestaciones de su interés en la firma de dicho convenio, finalmente suscrito por el ministro Escalante y el canciller peruano Joaquín José de Osmar, en abril de 1852 y ratificado en 1885. Para esto último, la Cancillería costarricense autorizó como encargado ad hoc a Crisanto Medida (Ministerio de Relaciones Exteriores del Perú, 23 de octubre 1856).

El 5 de agosto de 1856 el Gobierno peruano nombró a Pedro Gálvez como representante de su país para América Central, Nueva Granada y Venezuela (Ministerio de Relaciones Exteriores del Perú, 5 de agosto 1856). A partir de la revisión de la correspondencia diplomática de la época seleccionada para este estudio, se puede inferir que el ministro Gálvez era un defensor de la causa americana y que estaba convencido de los réditos que obtendría su país si apoyaba a las naciones centroamericanas en la lucha contra los filibusteros, en especial si se conseguía la victoria. En dichas comunicaciones el ministro Gálvez resaltaba la labor heroica de los costarricenses en la batalla contra las tropas invasoras e insistió en la necesidad de que el Perú apoyara al istmo en la contienda; así, solicitó el envío de vapores de guerra e intervino en favor del otorgamiento de un préstamo.

El 21 de enero de 1856, con el fin de obtener cooperación por parte del Perú, el Gobierno costarricense nombró como comisionados especiales, en este país sudamericano, a Nasario Toledo y Gregorio Escalante, para que, en nombre del Estado costarricense, solicitaran un empréstito para solventar los gastos de la guerra y, al mismo tiempo, efectuar acuerdos concernientes a la protección y defensa de las naciones hispanoamericanas (Ministerio de Relaciones Exteriores del Perú, 21 de octubre de 1856). Sin embargo, el señor Toledo se dedicó, especialmente, a las gestiones con Chile, en tanto el señor Escalante se enfocó en el Perú. 
El 31 de enero de 1857, producto de las negociaciones efectuadas entre el Perú y Costa Rica, el canciller costarricense Lorenzo Montúfar y el ministro Gálvez firmaron dos tratados, uno sobre la unión continental y otro de amistad, comercio y navegación (Ministerio de Relaciones Exteriores del Perú, 31 de enero de 1857). Además, tal fue la confianza depositada en el ministro Gálvez, por parte de Costa Rica, que se le acreditó como su representante ante el Gobierno de Guatemala, con una autorización para que acordara la manera de efectuar operaciones de guerra conjuntas contra los invasores de Nicaragua (Ministerio de Relaciones Exteriores del Perú, 23 de marzo de 1857). En relación con la Misión del Perú en Centroamérica y la lucha contra los filibusteros, el ministro Gálvez, en su comunicación del 23 de marzo de 1857 expresó lo siguiente:

En todo caso, la Misión del Perú en estos países, en circunstancias difíciles, es uno de los hechos más nobles que caracterizan al Gobierno del Perú, que ha difundido el consuelo y levantado de la postración a estos países, y que lo harán por siempre digna de las bendiciones de sus habitantes: y si el resultado de la guerra fuese desgraciadamente adverso a Centroamérica, y tuviese después que deplorar amargamente por las otras Naciones Hispanoamericanas, cabrá al Perú la satisfacción de haber llenado en lo posible sus deberes para sostener la justicia y los derechos de estos pueblos en una guerra de vandalaje. (Ministerio de Relaciones Exteriores del Perú, 23 de marzo de 1857)

Lo anterior permite identificar la importancia que tenía para el Perú apoyar a los pueblos de la región en su lucha contra la presencia norteamericana en Nicaragua, y ser reconocido como un Estado noble que cumplió con sus deberes, en un contexto en el que los países latinoamericanos buscaban evitar la intervención, tanto de agentes europeos como estadounidenses, en sus territorios.

\section{Intereses y preocupaciones del Perú y Costa Rica respecto a la campaña de $1856-1857$}

Tanto el Perú como Costa Rica manifestaron sus inquietudes e intereses en torno a la lucha contra los filibusteros. En tal sentido, en la comunicación suscrita por el presidente Mora en la que se nombra a los señores Nasario Toledo y Gregorio Escalante como Comisionados Especiales costarricenses cerca del gobierno del Perú, el mandatario aprovechó para exponer varias de sus preocupaciones, entre ellas la amenaza a la independencia de los Estados hispanoamericanos por parte de enemigos foráneos y la necesidad de recibir apoyo de los países sudamericanos, en especial, por medio de la concesión de créditos (Ministerio de Relaciones Exteriores del Perú, 21 de octubre de 1856). 
En una comunicación del 19 de diciembre de 1856, enviada por el Ministro Gregorio Escalante al Ministro de Relaciones Exteriores del Perú, manifestó que para el Gobierno de Costa Rica, además de la situación que se vivía en Nicaragua y que afectaba a toda América Central, eran de especial interés acontecimientos como la anexión de Texas por parte de los Estados Unidos y la ocupación de California por este mismo país, los cuales incrementan su inquietud y afán por defender el nacionalismo, la independencia y la soberanía de las naciones hispanoamericanas, así como la unión y fraternidad de los pueblos americanos, frente a los filibusteros. En virtud de lo anterior, apela a la similitud de intereses que compartía con otros países latinoamericanos para solicitarles su apoyo y colaboración. En tal sentido, considera de suma importancia la Confederación de los Estados hispanoamericanos, al proponer que Costa Rica sea el país sede para las reuniones que se efectuarían en el marco de esta alianza (Ministerio de Relaciones Exteriores del Perú, 19 de diciembre de 1856).

Asimismo, Costa Rica prestaba particular atención a la vía del tránsito y la posible construcción de un canal interoceánico en el istmo. Sin embargo, no era el único país interesado en estos aspectos. El Perú también había manifestado su preocupación por el control y uso de la mencionada ruta. Al respecto, el ministro Gálvez se refirió en los siguientes términos:

Está el interés universal que tan influyente vía de comunicación no cambie su carácter de vehículo de civilización, es el de instrumento fortísimo de explotación y de opresión: dominada por una potencia ávida y que tuviera en poco los derechos de los demás pueblos, los de la América Occidental verían comprometidos sus más caros intereses; especialmente el Perú, cuyas relaciones más esenciales de todo género tomarían completamente esta dirección en vez de la difícil vía del Cabo. (Ministerio de Relaciones Exteriores del Perú, 19 de diciembre de 1856)

Lo precedente reflejaba el fuerte interés del Perú en la existencia de una vía de comunicación que conecte el Pacífico con el Caribe, pues esto le facilitaría su salida al Atlántico, océano en el que no tiene litoral y, que de lo contrario, su único acceso sería bordeando el continente hasta el Cabo de Hornos, lo que implicaba un elevado costo en tiempo y dinero.

Por otra parte, la Legación del Perú en Costa Rica valoraba indispensable la negociación simultánea con los gobiernos de la región, así como con los europeos y los Estados Unidos; con la esperanza de conseguir apoyo en "todo el mundo civilizado" para la gran cuestión americana. Igualmente, el ministro Gálvez solicitó a su gobierno el envío de un vapor de guerra que serviría para trasladar a los funcionarios de su Legación a lo largo de Centroamérica, 
con la finalidad de que estos pudieran efectuar las negociaciones pertinentes (Ministerio de Relaciones Exteriores del Perú, 19 de diciembre de 1856). Estas propuestas se alinean con la profunda disposición del país sudamericano para proteger la independencia y dignidad de todos los Estados centroamericanos empleando recursos de todo tipo (Ministerio de Relaciones Exteriores del Perú, 15 de enero de 1856).

\section{Factores que influenciaron en el otorgamiento del empréstito}

\section{Generalidades}

En Costa Rica los recursos económicos se estaban tornando cada vez más escasos, dificultando sus labores de lucha y defensa frente a las tropas extrarregionales. Ante tal situación, el Gobierno solicita ayuda a Perú por medio del otorgamiento de "un préstamo de cuatrocientos o quinientos mil pesos, se aseguraría el reembolso del capital y de los intereses de la manera más segura y satisfactoria" (Ministerio de Relaciones Exteriores del Perú, 27 de abril de 1857). Esta exhortación era respaldada por el delegado peruano en Costa Rica, quién manifestó lo siguiente:

Sobre todo, la generosa y pronta consecución del empréstito solicitado por Costa Rica, elevaría muy alto la gloria del Perú y su influjo en estas regiones: en esta República hay sobrada decisión, pero faltan los medios para conducir las operaciones de la guerra con la celeridad y tenor que reclaman las circunstancias; los auxilios pecuniarios prestados oportunamente, asociándonos a sus honrosos triunfos que harían seguros al par que nos presentarían como los generosos defensores de la causa de América, de la libertad y de la justicia. (Ministerio de Relaciones Exteriores del Perú, 14 de enero de 1857)

A pesar de las opiniones favorables y las ventajas enumeradas por el ministro Gálvez, relativas a la concesión del empréstito, las autoridades peruanas demoraron la atención de la solicitud de Costa Rica por los problemas fiscales. Entonces el señor Escalante tomó la decisión de realizar una publicación, a título personal, en la prensa peruana, percibida como un ataque contra el presidente Ramón Castilla, para luego, partir del Perú, sin despedirse de sus jerarcas (Sáenz, 1996). Para fortuna de Costa Rica, el Gobierno peruano no le concedió mayor importancia y en marzo de 1857 fue autorizada la ayuda pecuniaria. Aunque como condición para la formalización del empréstito, se solicitó 
a Costa Rica remitir una satisfacción por el inoportuno proceder del señor Escalante, misma que fue proporcionada mediante una nota de fecha 14 de abril de ese año (González, 1925; Sáenz, 1996).

Como resultado de lo anterior, el 2 de julio de 1857 el Gobierno costarricense le proporcionó un poder al señor Manuel Cañas para suscribir el contrato del crédito junto con el ministro Gálvez, como representante del Perú (Ministerio de Relaciones Exteriores del Perú, 2 de julio de 1857), firma que se efectuó en Puntarenas, en el mes de julio (Sáenz, 1996). Asimismo, tras su ratificación en San José, durante ese mismo mes, se autorizó al cónsul general y comisionado especial de Costa Rica en el Perú, Tomás Conroy, para finalizar el convenio y recibir el dinero (Ministerio de Relaciones Exteriores del Perú, 3 de diciembre 1857).

Es importante señalar que las condiciones del empréstito fueron favorables para Costa Rica: el monto concedido fue de cien mil pesos, en moneda fuerte o letra de cambio, con una tasa de interés del $4.5 \%$ anual, pagadero en Londres, al vencimiento de cada año, por medio de una casa designada para tal fin, por un plazo de diez años (Ministerio de Relaciones Exteriores del Perú, 7 de julio de 1857). Estos fondos fueron girados por el Perú, a través una casa londinense, el 12 de abril de 1858; aproximadamente un año después de finalizada la guerra contra los filibusteros (Ministerio de Relaciones Exteriores del Perú, 13 de mayo de 1857). Sin embargo, la mayor parte de este capital no llegó a manos del Gobierno costarricense, debido a la desafortunada gestión realizada por Cristiano Medida, encargado de cobrar los fondos en la ciudad europea (Sáenz, 1996).

El pago de la deuda por parte de Costa Rica debió efectuarse a inicios del año 1868, aunque no se concretó y en ese momento el Perú no presentó ningún reclamo. No obstante, durante la Guerra del Pacífico con Chile, en 1879, el Perú solicitó el pago correspondiente (González, 1925) para ello, el Gobierno peruano envió al ministro Tomás Lama como encargado de efectuar el cobro del dinero. Para ese entonces, el total de la deuda más sus intereses ascendía a US\$ 194 500,00; sin embargo, el monto realmente pagado por Costa Rica fue de US\$ 173 585, 49; es decir, hubo un descuento de alrededor de US\$ 21 000,00 (Ministerio de Relaciones Exteriores del Perú, 13 de mayo de 1857). Por escasez de efectivo y el escenario bélico, el pago se realizó con armas: "6 mil rifles sistema remington calibre 43 y sus respectivas municiones como parte del pago de la deuda (nuevo y buena calidad)." (Ministerio de Relaciones Exteriores del Perú, 16 de julio de 1879). Además, el Perú compró 10 mil rifles a El Salvador, cuyo pago lo debió efectuar Costa Rica por cuenta del empréstito que le había proporcionado el Perú (Ministerio de Relaciones Exteriores del Perú, 12 de abril de 1879). 


\section{Razones sobre Costa Rica}

La justificación expuesta por Gálvez en torno a por qué Costa Rica merecía la ayuda del Perú, se centran en la conceptualización de una imagen de país "digno", descrito dentro de los términos de la valentía y el éxito (incluyendo una posible retribución), valores y actitud congruentes con la ideología peruana y la promesa de devolver la suma de forma eficiente. En cuanto a la valentía, se expone como una cualidad costarricense ante, no solo los filibusteros, sino la naturaleza misma, como se observa en el fragmento:

Es difícil hacer justicia al heroísmo con que han luchado; más que contra la fuerza de los hombres, contra la naturaleza salvaje en que los elementos obran con toda su violencia. (...) Hundiéndose hasta las rodillas y teniendo muchas veces que asirse unos a otros, para no quedar sepultados en el fango. (Ministerio de Relaciones Exteriores del Perú, 2 de febrero de 1857)

Respecto al éxito del país centroamericano frente al ejército filibustero, Gálvez menciona que: "La Providencia recompensó los esfuerzos de los costarricenses como ellos lo merecían; pues no sólo consiguieron el éxito más completo en sus operaciones sobre los vapores y fuertes, sino que tomaron comunicaciones que los han puesto a cubierto" (Ministerio de Relaciones Exteriores del Perú, 27 de abril de 1857). De manera concluyente, ambos argumentos son expuestos en el siguiente texto:

(...) la victoria nunca podrá abandonar a los costarricenses que combaten como los pueblos heroicos de la antigüedad. A la distancia dificultante podrán apreciarse cual merecen las virtudes de ésta pequeña República que puede señalarse como modelo a los demás Estados Hispano-Americanos. Su población no llega a ciento cincuenta mil almas... en lo que en otras partes apenas se contaría para una gran provincia, forma un Estado que ve acrecentarse su prosperidad de día en día por la laboriosidad de sus hijos, y que ya sabe hacerse admirar y respetar por el entusiasmo con que todos hablan de su Patria, y por su resolución firme a sacrificarse por ella. (Ministerio de Relaciones Exteriores del Perú, 27 de abril de 1857)

En cuanto a valores, Gálvez recalca la imagen de país laborioso y esforzado, incluso con falacias de generalización como: "Todos los costarricenses están consagrados al trabajo y tienen una propiedad no habiendo entre ellos, ni ociosos ni mendigos; todos piensan en la tierra que han de cultivar." (Ministerio de Relaciones Exteriores del Perú, 27 de abril de 1857). Para terminar de fortalecer la imagen de país "digno", expone la idea de orden y respeto, así como su actitud cívica reflejada en el compromiso con el deber de la defensa del Estado (a 
pesar de que, en el momento de la imposición del impuesto, la reacción de los ciudadanos no fue aceptada de manera generalizada):

El Gobierno, apremiado por las circunstancias, decreta un alto impuesto sobre la exportación del café que es casi la única entrada del país, y este impuesto que hubiera podido causar una revolución porque comprometía la agricultura y el comercio, no es comentado por el vulgo: la juventud y las masas se abstienen de hablar de una cosa que no comprenden; más los padres de familia que son los hombres de valer, se dirigen al Presidente para exponerle; con modesta franqueza las funestas consecuencias del decreto, mostrándose dispuestos a llenar los vacíos del tesoro mediante un empréstito voluntario; con lo que todo se remedia sin insolentes recriminaciones del pueblo, sin insensata resistencia del poder, y sin el menor ruido por la prensa. (Ministerio de Relaciones Exteriores del Perú, 27 de abril de 1857)

Respecto al pago del empréstito, Sebastián Llorente, de parte del presidente Mora, asegura el pago del capital e impuestos de forma "segura y satisfactoria". De igual manera, el ministro Gálvez escribió: "Nunca un empréstito puede otorgarse con una convicción más profunda de que se presta un servicio inapreciable y de que el beneficio no será perdido." (Ministerio de Relaciones Exteriores del Perú, 27 de abril de 1857)

\section{Razones para el Perú}

En primer lugar, se encontraron motivos que tienen relación directa con el reconocimiento, de forma interna; identificándose al pueblo peruano con el valor de la generosidad, razón por la cual, siendo consecuentes, deberían acceder a la petición costarricense. Y de forma externa, exponiendo el empréstito como una oportunidad para mostrar a la región centroamericana un Perú "salvador":

En consecuencia, sobrarán hombres y valor, pero carecerán de otros recursos, principalmente de dinero: y he allí la ocasión en que Perú está llamado a presentarse como salvador de la América Central (...) no haría el Perú sino sostener el gran nombre y el primer rango entre las Repúblicas HispanoAmericanas que ha adquirido dignamente en estos países. (Ministerio de Relaciones Exteriores del Perú, 27 de abril de 1857)

La idea de proyectar esta imagen internacional del Perú como "salvador", se fortalece con la supuesta facilidad con la que Perú podría otorgar el préstamo a Costa Rica: “(...) sin hacer más sacrificio que auxiliarlos con simples empréstitos y que para estos pueblos serán un inmenso favor, y para el Perú no serán una 
verdadera pérdida" (Ministerio de Relaciones Exteriores del Perú, 27 de abril de 1857). Otra razón relacionada con inversión monetaria es la posibilidad de la pérdida de Costa Rica contra los filibusteros, con lo cual Gálvez supone que el país suramericano tendría que realizar una inversión mayor para frenar una expansión creciente que podría terminar por amenazar al Perú y sus intereses:

Esto se presenta más palpable cuando se piensa en que, el Perú y todas las Repúblicas Hispano-Americanas, tenían que, o doblar o servir y postrarse vilmente ante la conquista de una de sus hermanas que después traería la de ellas, o tendrían que reconquistar el país perdido gastando millones de vidas y millones de pesos. (Ministerio de Relaciones Exteriores del Perú, 2 de febrero de 1857)

La idea principal respecto a la contienda fue señalar que se trataba de una "causa justa”, en la que un país débil y pequeño, se enfrentaba a un ejército proveniente de un país norteamericano con gran poder militar y con deseos expansionistas. Esta idea se expresa en el siguiente extracto:

Un pueblo que tiene tanta abnegación, que aprende a ser valiente consagrándose al trabajo y que desea el engrandecimiento de la Patria, convencido de que no obstante su pequeñez actual, le espera un brillante porvenir (...) Sería necesario renunciar a todas las simpatías para con los pueblos Americanos, principalmente hacia a las Repúblicas hermanas (...) todo homenaje a la virtud, por la civilización para no tenderle una mano generosa cuando sostiene la gran causa de América con tanto heroísmo. (Ministerio de Relaciones Exteriores del Perú, 27 de abril de 1857)

Finalmente, Gálvez propone la máxima de "cumplir con el deber de auxiliarlos eficazmente", esto, inscrito en el marco histórico del Tratado Continental; se concretan las siguientes razones en el ámbito de interés comercial y de posicionamiento geográfico (siempre en el año 1857, cabe recordar que el tratado se firma antes de la conclusión de la campaña): "Que el Perú tenía intereses comunes con los de Centroamérica, relativamente al comercio y navegación (...) Que si llegaba a efectuarse, alguna comunicación interoceánica a través de cualquiera de los Estados de Centro-América, el Perú se consideraría tan interesado como ellos (...)" (Ministerio de Relaciones Exteriores del Perú, 27 de abril de 1857). 


\section{Análisis de las razones que motivaron el em- préstito peruano a Costa Rica}

A pesar de la situación coyuntural en la que se encontraba Perú, el pedido hecho por el Gobierno de Costa Rica de ayuda monetaria, mediante un préstamo, para afrontar los costos relacionados con el enfrentamiento de los filibusteros, encuentra una respuesta afirmativa; asociada a los intereses del país suramericano en la zona, la intención de conformar bloques mayores para la protección de posibles invasores de países hispanoparlantes (como se expuso con el Destino Manifiesto, por ejemplo), y los motivos presentes en la correspondencia por parte del Ministro Pedro Gálvez.

Aunque el empréstito se concretó después de finalizada la campaña contra los filibusteros y el monto recibido fue inferior a lo solicitado por parte Costa Rica, la ayuda peruana llegó en un momento en que el Estado costarricense debía hacer frente a una economía posguerra. Además, es reflejo de las buenas relaciones entre ambos países, los cuales eran signatarios de la Confederación de Estados Hispanoamericanos que buscaba el respeto a la integridad y la soberanía de cada país, frente a posibles invasiones extranjeras.

Los motivos por los cuales se considera que Costa Rica es merecedor del empréstito por parte del Perú, descritos por el ministro Gálvez, pueden ser ubicadas en tres grupos, el primero, se refiere a razones características del país centroamericano, el segundo, a rasgos de la contienda (por lo que vale o no la pena luchar) y el tercero, a cualidades del Perú.

De esta manera, en el primer grupo Costa Rica se propone como "digno" de la ayuda peruana porque: es valiente; es decir, los hechos han comprobado que es un país que lucha y que no desperdiciaría el apoyo peruano. Además, se ha confirmado que está teniendo éxito, con lo cual la ayuda peruana no solo está del lado victorioso, sino que tiene mayores posibilidades de retribución. También, poseen los costarricenses, valores y actitudes congruentes con el Perú, o con el imaginario peruano, de lo que constituye un país que vale la pena y, finalmente, ofrecen una promesa de pago seguro. En el segundo grupo, sobre la contienda, se señala que es una causa justa, donde el país débil defiende la causa de la independencia contra el expansionismo, con lo cual se justificaría la ayuda peruana.

En el tercer grupo se encuentran argumentos que apelan directamente al Perú, como: reconocimiento, amenaza, deber y poder. El reconocimiento se puede expresar de dos formas: una visión interna y otra externa; es decir, lo que los peruanos creen que forma parte de su idiosincrasia y lo que proyectan al mundo. 
En tal sentido, el empréstito representa una oportunidad para demostrar la nobleza y generosidad del Perú con Costa Rica; país que había sido descrito como bueno y heroico. Además, el ministro Gálvez en su correspondencia lo presenta como una opción favorable para promover la imagen idílica del Perú como "el salvador" de Centroamérica y como una expresión de conveniencia, porque no significa un gran esfuerzo para el Perú, pero sí es muy bien visto por Centroamérica y, en especial, por Costa Rica. Esto supone que la intención de ayuda se plantea como un medio para mejorar la proyección internacional de una imagen positiva del Perú en la zona.

La amenaza también se plantea desde dos vertientes, por una parte, se propone que los filibusteros pudieran resultar un peligro para el Perú, incluso, si de alguna forma no se detiene su expansión; y que la inversión económica del Perú podría tener que ser mayor si Costa Rica no tiene la victoria en ese momento, porque después se tiene que reconquistar algún sitio. También se expone el sentido de cumplir con el deber, que parece ser expuesto en el sentido kantiano del "deber ser"; auxiliar a Costa Rica de forma eficaz, implica que debe ser una ayuda oportuna y suficiente.

El último de los argumentos, que se relaciona con el poder, se expone dentro de las negociaciones del Tratado Continental, donde se inicia una clara intención de comercio entre las partes, tal como la modificación de aranceles y la promoción de las exportaciones, pero también se señala un elemento clave: el canal. La correspondencia demuestra que existió la posibilidad de aprovechar la posición geográfica de Costa Rica para la creación de un canal interoceánico que facilitara la comunicación y el paso de bienes, ruta que beneficiaría al Perú.

Además, es importante notar que las argumentaciones para otorgar el empréstito peruano a Costa Rica evolucionaron en la correspondencia de Gálvez, partiendo de las razones del primer grupo, es decir, las que describen a Costa Rica, hacia los motivos del tercer grupo, que justifican por qué el Perú debería acceder al préstamo. Esto sucede gracias a la gestión diplomática en la que Pedro Gálvez ocupa un papel fundamental.

La falta de información sobre este tema en Costa Rica es evidente, no como mención del hecho histórico, porque se ha escrito gran cantidad de artículos en torno a la campaña de los filibusteros, sino la carencia de documentación oficial al respecto, misma que sí fue ubicada en el Ministerio de Relaciones Exteriores del Perú y digitalizada a partir de imágenes tomadas de las cartas originales, donde, además del contenido, es posible identificar tipologías y firmas; lo que constituye parte de la memoria de un episodio clave en la construcción de las relaciones diplomáticas entre ambos países. Por lo tanto, se recomienda realizar 
investigaciones relacionadas con el resguardo de la información histórica en general $\mathrm{y}$, de forma particular, investigar acciones específicas en coyunturas cruciales para la historia de los países, tal como es el caso de la gestión de los fondos provenientes de Perú, aspecto que podría contribuir a dimensionar los efectos de este tipo de acciones en las relaciones presentes y futuras entre ambos Estados.

En estudios posteriores sobre la historia de los lazos diplomáticos entre Costa Rica y el Perú se podrían analizar las posibles repercusiones que los acontecimientos estudiados hayan tenido en las relaciones entre ambos países; por ejemplo, la existencia de una escuela en San José llamada, actualmente, Escuela Unificada República del Perú Vitalia Madrigal Araya, la cual adoptó el nombre de Escuela República del Perú a inicios del siglo XX, como reconocimiento al empréstito otorgado por este país en 1857 y, la cual sigue siendo un ícono importante de las relaciones entre Costa Rica y el Perú. En tal sentido, podría ser de interés estudiar más a profundidad acontecimientos como este e identificar si además de este hecho se ha presentado algún otro vinculado a lo sucedido durante esta época de la historia y que contribuyan con un entendimiento más detallado de la política exterior de Costa Rica y la construcción de sus relaciones bilaterales.

\section{Referencias}

Ayllón, F. (2017). Castilla y Marquesado Ramón. Museo del Congreso y la Inquisición. http:/www.congreso.gob.pe/Docs/participacion/museo/congreso/files/ files/1864-ramon-castilla.pdf

Barbé, E. (2007). Relaciones Internacionales. Tercera Edición. Madrid, Editorial Technos.

Basadre, J. (2005). Historia de la República del Perú (1822-1933). Tomo 3, p. 140197. El Comercio S. A.

De la Reza, G. (2014). ¿Necesidad o virtud? Razones y alcances de los tratados continentales hispanoamericanos de 1856. ISSN 0252-8894. UAM. México.

Fallas, C. (2011). El filibusterismo en los mensajes al congreso de los presidentes de los Estados Unidos y la ley de neutralidad 1848-1860. Diálogos Revista Electrónica de Historia. ISSN: 1409- 469X. Vol. 12 N² 2. p. 70-97.

Fallas Santana, C. (2004). Elite, negocios y politica en Costa Rica 1849-1859. Museo Histórico Cultural Juan Santamaría.

Fallas Santana, C. (2015). Costa Rica frente al filibusterismo: la guerra de 1856 y 1857 contra William Walker: defensa y fortalecimiento de las instituciones 
del Estado. Serie de cuaderno de historia de las instituciones de Costa Rica, v. 26, 1era edición. Editorial Universidad de Costa Rica.

Garibaldi, R. (2003). La política exterior del Perú en la era de Ramón Castilla. Defensa hemisférica y defensa de la jurisdicción nacional, pp. 252-298.

González V., C. (1925). El empréstito peruano a Costa Rica. Revista de Costa Rica, $6,117$.

Quesada, J. (2014). Contribuyentes del 56. Revista del Colegio de Licenciados y Profesores en Letras, Filosofía, Ciencias y Artes. ISSN 1409-1534.

Ministerio de Relaciones Exteriores del Perú. (s.f.a). Archivo Central, Series Correspondencia. Folio 01.

Ministerio de Relaciones Exteriores del Perú. (s.f.b). Archivo Central, Serie Correspondencia. Caja 77, file 12.

Ministerio de Relaciones Exteriores del Perú. (15 de enero de 1856). Archivo Central, Serie correspondencia Oficio N. ${ }^{\circ}$ 4, 08 folios.

Ministerio de Relaciones Exteriores del Perú. (5 de agosto de 1856). Archivo Central, Correspondencia diplomática. Folio 01.

Ministerio de Relaciones Exteriores del Perú. (21 de octubre de 1856). Archivo Central, Correspondencia diplomática, 02 folios.

Ministerio de Relaciones Exteriores del Perú. (23 de octubre de 1856). Archivo Central, Serie Correspondencia. Caja 96, file 4. Cód. 6. San José.

Ministerio de Relaciones Exteriores del Perú. (9 de noviembre de 1856). Legación del Perú en los Estados Unidos 1841-1898. Archivo Central. Caja 53, libro 66. Washington.

Ministerio de Relaciones Exteriores del Perú. (19 de diciembre de 1856). Oficio N. ${ }^{\circ}$ 1 de la Legación del Perú cerca de las Repúblicas de Centro América. Archivo Central. Series correspondencia diplomática, 10 folios.

Ministerio de Relaciones Exteriores del Perú. (31 de enero de 1857). Archivo Central, Correspondencia diplomática. Oficio Núm. 4, 08 folios.

Ministerio de Relaciones Exteriores del Perú. (2 de febrero de 1857). Correspondencia diplomática. Archivo Central.

Ministerio de Relaciones Exteriores del Perú. (14 de enero de 1857). Informe de Pedro Gálvez . Archivo Central, Serie correspondencia, caja 99, file 6. Cód. 5-9. Puntarenas.

Ministerio de Relaciones Exteriores del Perú. (14 de enero de 1857). Informe de Pedro Gálvez. Archivo Central. Series Correspondencia. Caja 103, file 9. Cód. 5-9. Puntarenas. 
Ministerio de Relaciones Exteriores del Perú. (2 de febrero de 1857). Oficio N. ${ }^{\circ} 6$, de la legación del Perú cerca de las Repúblicas de Centro América. Archivo Central, Serie correspondencia, 12 folios.

Ministerio de Relaciones Exteriores del Perú. (23 de marzo de 1857). Oficio N. 9 de la legación del Perú cerca de las Repúblicas de Centroamérica.Archivo Central, Series correspondencia, 14 folios.

Ministerio de Relaciones Exteriores del Perú. (27 de abril de 1857). Anexo al oficio N. ${ }^{\circ} 25$ de la Legación del Perú cerca de las Repúblicas de Centroamérica. Archivo Central, Series de correspondencia diplomática, 31 folios.

Ministerio de Relaciones Exteriores del Perú. (27 de abril de 1857). Archivo Central, Serie correspondencia. Oficio N. ${ }^{\circ} 24,07$ folios.

Ministerio de Relaciones Exteriores del Perú. (13 de mayo de 1857). Oficio N. ${ }^{\circ} 26$, de la legación del Perú cerca de las Repúblicas de Centro América. Archivo Central, Serie correspondencia, 31 folios.

Ministerio de Relaciones Exteriores del Perú. (2 de julio de 1857). Nota del Ministerio de Relaciones Exteriores de Costa Rica. Archivo Central. Serie correspondencia, 02 Folios.

Ministerio de Relaciones Exteriores del Perú. (7 de julio de 1857). Archivo Central. Protocolo de la negociación del empréstito, 02 folios.

Ministerio de Relaciones Exteriores del Perú. (3 de diciembre de 1857). Archivo Central. Series Correspondencia Diplomática, 02 folios.

Ministerio de Relaciones Exteriores del Perú. (12 de abril de 1879). Archivo Central serie Correspondencia diplomática, caja 267, file 2, cód. 5-9. Lima.

Ministerio de Relaciones Exteriores del Perú. (16 de julio de 1879). Archivo Central, serie correspondencia, caja 267, file 2, cód. 5-9. Lima.

Molina, I. (2006). En defensa del análisis histórico. A propósito de algunas obras recientes sobre la guerra de 1856- 1857 contra los filibusteros. Revista de Historia de América, 137, p. 211-227. https:/www.jstor.org/ stable/20140169?seq=1

Sáenz C., J. (1996). Historia diplomática de Costa Rica (1821-1910). Editorial Juricentro.

Valdivia, J. (1874). Memorias sobre las revoluciones de Arequipa desde 1834 hasta 1866. Imprenta de la opinión nacional. Perú.

Weinberg, Albert K. (1968). Destino Manifiesto. El expansionismo nacionalista en la historia norteamericana. Buenos Aires, Editorial Paidós. 
